\title{
http://artnodes.uoc.edu
}

\section{Agencia, imágenes e índex en las fotopinturas de Gerhard Richter: los cuadros como artefactos visuales}

\author{
Víctor Murillo Ligorred \\ Universidad de Zaragoza
}

Fecha de presentación: febrero de 2018

Fecha de aceptación: abril de 2018

Fecha de publicación: junio de 2018

\section{Cita recomendada}

Murillo, Víctor. 2018. «Agencia, imágenes e índex en las fotopinturas de Gerhard Richter: los cuadros como artefactos visuales". Artnodes. N. ${ }^{\circ} 21: 225-232$. UOC [Fecha de consulta: dd/mm/aa]. http://dx.doi.org/10.7238/a.v0i21.3196.

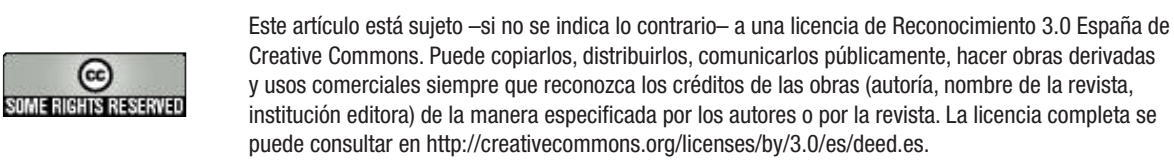

\section{Resumen}

El presente texto aborda el estudio de la obra pictórica de Gerhard Richter en términos de índex, una lectura actual que interpreta la naturaleza mecánica de sus pinturas desde lo icónico. Para ello, primeramente, se estudia la conexión directa entre la obra de las fotopinturas de los años sesenta y setenta de Gerhard Richter con el concepto de índex, desde la relación de causalidad que establece, donde Richter esconde la mano del pintor y muestra la huella del aparato. En segundo lugar, a través de la estética fotográfica que desarrolla en su imaginario, se analizan de forma clara los mecanismos y procedimientos que utiliza para conservar la ilusión de imagen foto, convirtiendo esas imágenes en artefactos visuales. Para, en tercer lugar, demostrar cómo el concepto de índex es el término más adecuado para explicar la naturaleza foto-pictórica de estas obras. El desleimiento de las figuras a través de los barridos intencionados, la mecanicidad de la técnica, el amateurismo identificado en el antiestilo y la negación del propio medio pictórico traen al frente unas imágenes de apariencia fotográfica que 


\title{
artnodes
}

http://artnodes.uoc.edu

Agencia, imágenes e índex en las fotopinturas...

nos hacen reflexionar sobre la propia naturaleza de su medio, la memoria, la representación

y lo icónico.

Palabras clave

índex, antiestilo, fotopinturas, mecanicidad, Gerhard Richter

Agent, images and índex Gerhard Richter photo-paintings: paintings as

visual devices

\begin{abstract}
The present text deals with the study of the pictorial work of Gerhard Richter in terms of index, a current reading that interprets the mechanical nature of his paintings from the iconic. To this end, the direct connection between Gerhard Richter's photo-paintings from the sixties and seventies is studied with the concept of index, from the causality relationship that it establishes. For this, Richter hides the hand of the painter and shows the trace of the device. Secondly, through the photographic aesthetics that he develops in his imaginary, the mechanisms and procedures he uses to conserve the illusion of photo image are clearly analyzed, converting those images into visual artifacts. Thirdly, it is explained how the concept of index is the most appropriate term to explain the photo-pictorial nature of these works. The descent of the figures through intentional sweeps, the mechanicity of the technique, the amateurism seen in the anti-style and the denial of the pictorial medium itself, bring to the forefront some images of photographic appearance that make us reflect on the very nature of their medium, memory, representation and the iconic.
\end{abstract}

\section{Keywords}

Index, anti style, photopainting, mechanicity, Gerhard Richter

\section{Introducción. De la pintura tradicional a la mecanicidad de la pintura}

En las postrimerías de la modernidad y los albores de la posmodernidad, Gerhard Richter comienza a gestar un nuevo sistema de trabajo en torno a su producción pictórica, en el que abandona radicalmente las formas de hacer de los pintores tradicionales. A partir del año 1962, tras su llegada como emigrante a la República Federal Alemana, Richter rehúye de su forma de trabajar desarrollada en la RDA durante su etapa de formación, al descubrir otros artistas alemanes como Polke o Lueg, así como la obra de Warhol o Twombly que, a pesar de encontrarse en otros contextos sociales y geográficos ya realizaban obras pictóricas a partir de la utilización de fotografías. La insolencia con la que se enfrentaban a las obras de arte fue una de las cosas que más llamó la atención de Richter. Este nuevo panorama cultural propició que Richter destruyese toda su obra anterior, en un gesto tomado como una verdadera declaración de intenciones, para embarcase en un proyecto pictórico de nueva factura en gran intimidad con el documento fotográfico. Estos proyectos de hibridación entre la imagen fotográfica y la imagen pictórica surgen de manera compartida con otros artistas en la década de los sesenta y, en el caso que nos ocupa, tienen que ver con una utilización de lo fotográfico en relación con una suplantación de lo pictórico. El propio Richter, recurrentemente, siempre alude al hecho de que todo aquel que maneja fotografías pinta a partir de ellas de un modo u otro. Su afición a la fotografía, así como su paso por el laboratorio de un fotógrafo profesional, marcan la manera de enfrentar el cuadro pintado en su nueva etapa en la RFA y que se extiende hasta la actualidad.

En ello, Richter se centra en reproducir imágenes fotográficas ya existentes, en una suerte de documentos encontrados, que le sirven como base de su imaginario. Un material documental de diversa procedencia, como la prensa, los archivos policiales o los álbumes familiares, desprovistos de cualquier aura artística, que utiliza para pintar sus cuadros. Esto es, fotografías domésticas o periodísticas sin ningún tipo de interés artístico, totalmente anodinas en muchos casos, le sirven para comenzar su nuevo proyecto pictórico. Así, el pesado carácter fotográfico de sus modelos revierte de forma directa en su propia manera de entender el cuadro. Su verdadero deseo es realizar una fotografía con pintura. Ese es el efecto que Richter espera conseguir a través de la utilización de modelos preexistentes traídos 


\section{artnodes}

http://artnodes.uoc.edu

Agencia, imágenes e índex en las fotopinturas...

de la imagen foto, que nada tiene que ver con la visión subjetiva de un pintor. No crear nada, sino trasladar lo que existe previamente al lienzo. Cómo hacerlo se traduce en un proceso mecánico que se gesta no desde la mano del pintor, sino desde la propia huella del aparato que lo invade todo. En este sentido, Richter comenta:

«Ya no se podría creer en el cuadro pintado: su presentación ya no estaba viva porque no era auténtica, sino inventada [...] La fotografía es la imagen más perfecta: no cambia, es absoluta y por tanto autónoma, incondicional y carente de estilo. En la manera en que habla y en lo que dice, la tomo como modelo» (Richter 2003, 16).

De hecho, comienza a pintar desde el convencimiento de realizar fotografías con pintura. Por tanto, el resultado no son cuadros tradicionales desde el punto de vista de la composición y el encaje, sino una suerte de fotografías pintadas de nueva factura que aportan una visión concreta de los objetos. Este es el cambio de paradigma y la novedad en su obra.

El hecho de pintar fotografías entra en el territorio, primeramente, del amateurismo, como práctica artística en boga del momento. Esta característica es distintiva en Richter y, aunque esta estrategia es librada con el virtuosismo que también le caracteriza -es un maestro de todas las pinturas (Danto 2002, 160)-, no es por lo que se distingue esta nueva etapa. Sin embargo, y aquí radica la novedad, Gerhard Richter tiene -la ilusión- intención de crear fotografías con pintura, en lugar de crear cuadros pintados en términos tradicionales (Germer 1987, 7). Del Río señala que en Richter «el discurso artístico se abre así a la imagen fotográfica por una vía de suplantación de lo pictórico» (Del Río 2008, 80). La cuestión de fondo no se traduce en pintar fotografías, sino en crear fotografías con pintura.

Si como Richter afirma, asumimos que el artista no pinta, sino que por el contrario, la base de su trabajo es la de crear fotografías con pintura, estamos de acuerdo en que su trabajo remite únicamente a una transposición de términos, esto es, a un deslizamiento punto por punto, de la imagen foto, a la imagen cuadro:

«El hecho de copiar fotografías (en lugar de ampliarlas mediante técnicas fotomecánicas, por ejemplo) no tiene nada de raro. Todos los que manejan fotografías pintan a partir de ellas de una manera u otra. Poco importa que lo hagan con el pincel, en un collage, por serigrafía o sobre lienzo. Ahora bien: lo que sí puede parecer extraño es que yo quiera producir precisamente este tipo de cuadros y ningún otro, cuadros que actualmente solo puedo producir de esta manera» (Richter 2003, 16).

A través de los empastes y los distintos registros, los pintores han conseguido crear imágenes visionarias que no pueden confundirse ni con la realidad, ni entre ellas mismas (Rose 2003, 156). Sin embargo, Richter tiene como objetivo no distinguirse de la fotografía. Por ese motivo difumina, iguala, homogeniza y oculta el registro del pintor, para mostrar la huella del aparato fotográfico.

\section{Las fotopinturas entendidas en términos de índex: el antiestilo como estrategia de trabajo}

Este artículo presenta las fotopinturas en tanto que índex. Se atiende a estas obras desde la lógica de la huella fotográfica, en su origen mecánico, desligado de la técnica pictórica tradicional. A través de él, Richter crea una obra con pintura en forma de fotografía. Para ello, una de las estrategias que sigue el pintor se fundamenta principalmente en el antiestilo. Richter realiza una obra neutra, homogénea, alejada de la historia de la pintura, donde lo que interesa no es mostrar la mano del pintor, sino la huella del aparato. De este modo, se muestra una obra mecánica, donde la tecnicidad a través de la ausencia de empastes, y la cualidad vibrante de los barridos, emergen como características principales de esas imágenes. Por tanto, para comprender estos procedimientos y mecanismos de su trabajo, debemos atender a los siguientes niveles de estudio:

Primero. Richter muestra una mecanicidad de la pintura que, lejos de encontrarse en los cauces de la historia de la práctica pictórica, señala directamente hacia un antiestilo propio de la fotografía y lo fotográfico. Es decir, Richter no crea pinturas en el sentido de la historia del arte, sino que consigue crear pinturas en tanto que fotografías. El propio Richter argumenta su decisión de pintar a partir de fotografías y de hacerlas:

«Pintar a partir de una fotografía forma parte del proceso de trabajo. No es una característica distintiva de mi visión, es decir, no sustituyo la realidad con una reproducción de ella, con un mundo de segunda mano. Yo recurro a la fotografía como Rembrandt recurrió al dibujo y Vermeer a la cámara oscura, para hacer un cuadro. Podría prescindir de la fotografía y el resultado seguiría presentando el aspecto de una fotografía copiada. Así, de hecho, los conceptos "reproductivo" o "directo" carecen de sentido» (Richter 2003, 18).

Al mismo tiempo que intenta crear fotografías con pintura, asume su dificultad (como imposibilidad) de la creación de una fotografía con pintura, y sentencia al respecto: "Soy un surrealista» (Richter 2003 , 20). En su investigación como pintor llega a la conclusión de que la fotografía le facilita la tarea de hablar de una realidad que puede ignorar y no juzgar a través de ella misma. La fotografía es, en este sentido, el medio para que Richter pinte la realidad a través de un documento, por el cual trae al frente un discurso sin un cuestionamiento ideológico (aparentemente). A lo que añade: «La fotografía me sirve como documento sobre una realidad que ignoro y que no juzgo, que no me interesa y con la que no me identifico» (Richter 2003, 20). 


\section{artnodes}

http://artnodes.uoc.edu

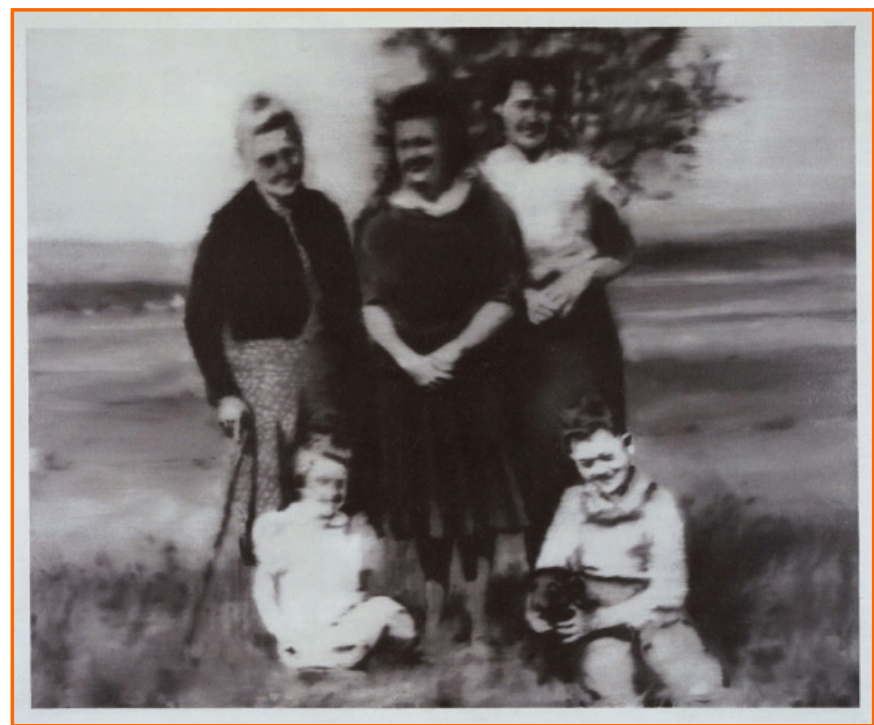

Imagen 1. Gerhard Richter. Family. Óleo sobre lienzo. 1968

Richter pinta, 0 crea, un mundo fotografiado en el sentido que lo expresa Lang $(1995,34)$. Solo es posible pintar como él lo hace. Donde todo está mediado por el aparato fotográfico, solo cabe hacer pinturas como fotografías, o mejor aún, fotografías con pintura. El uso de las imágenes que maneja, y la representación que hace de ellas, trasciende a la propia semejanza en el sentido de Foucault (Foucault 2006, 74). Richter crea un tipo de pintura que, partiendo de esa suerte de imágenes encontradas, estas se convierten en pinturas ready-made. Es decir, traslada la imagen, punto por punto, desde la objetividad de la foto a la objetualidad del cuadro. Su voluntad se encuadra en recomponer la fotografía en pintura o la pintura en fotografía. Difumina, emborrona y homogeniza la imagen de tal forma que no aparezca el estilo, sino el antiestilo. El pintor mismo, en su intento de justificar la manera de hacer, condiciona la representación al explicar que, aun prescindiendo de la fotografía -entendida en este caso como modelo-, la imagen seguiría pareciendo una foto. Esto es, desde la propia concepción de la obra, el cuadro es fotográfico: su encuadre, su perspectiva, su anticomposición, su antiestilo... Todo lo que aparece en la imagen es fotografía, puesto que nada puede escapar a ella y nada debe entenderse fuera de la misma.

Segundo. Por tanto, si Richter pinta de una forma mecánica, del mismo modo que una cámara hace fotografías, Richter muestra la huella de esa fotografía, no una pintura convencional. Traslada, como decimos, punto por punto la imagen fotográfica a la superficie del lienzo, y en este proceder, su pintura debe ser entendida como un índex. De hecho, sus pinturas son índex en la medida en que no añaden nada al cuadro que no estuviese previamente en la foto, $y$ en ello, aparecen como la huella de la imagen que imitan. El índex no se encuentra en este caso en la mecanicidad del proceso, sino que, por el contrario, el índex es la huella de la foto deslizada al cuadro, eso sí,
Agencia, imágenes e índex en las fotopinturas...

de forma mecánica. Luc Lang escribe, a propósito de esta relación con Io indicial en Richter, lo siguiente: «En la obra de Richter, el carácter de la fotografía como signo indicial sirve para ofrecerle una especie de indiferencia visual 0 anticomposición» (Lang 1995, 34). En este mismo sentido, Edwards también sostiene que Richter crea fotografías con pintura creando una obra ready-made (Edwards 2007, 32-33). La conexión con la conceptualización del término duchampiano se establece en este momento, a través de los ready-made en tanto que índex, una condición alcanzada desde la mecanicidad de la técnica y el antiestilo. Aquí, surge en la descontextualización de esa imagen primigenia, llevada a los territorios de la pintura, punto por punto y a través de la categoría indicial, convirtiendo una imagen anodina en una imagen cuadro, con lo que esto supone.

«Richter hace pinturas de fotografías como imágenes de pinturas. Al emplear fotografías para hacer pinturas ready-made, se considera que Richter ha vaciado de sentido muchas de las afirmaciones del legado moderno: la plenitud orgánica cede el paso a la vacuidad; y las afirmaciones del sujeto expresivo se vacían al tiempo que la huella de la mano del artista cede el paso a la huella del aparato» (Edwards 2007, 32-33).

Este ceder el paso a la huella del aparato es la verdadera clave. El índex aparece en tanto que es la huella de la imagen en el cuadro. Asimismo, Luc Lang también apunta: «Si la representación ya no puede aparecer en la pintura sin una alusión a la fotografía, entonces Richter pintará un mundo fotografiado» (Lang 1995, 35). La fotografía es la excusa perfecta para poder huir de una idea clásica de pintura. Los objetos encontrados sirven para que el pintor no realice una composición, no tenga la responsabilidad de posicionarse ideológicamente ante un tema. La pintura ready-made centra el debate en la vacuidad, en la trasposición de términos punto por punto, que liberan al pintor del peso de la representación. Ya no había que creer en el cuadro pintado, tan solo realizar fotografías con pintura. No en el sentido de un mundo de segunda mano, sino en el verdadero sentido de que todo nuestro pensamiento es fotográfico.

Osborne sitúa la pintura de Richter como un índice histórico de las relaciones entre las esferas de la imagen fotográfica y pictórica (Osborne 1992, 109), es decir, la relación existente entre fotografía y pintura solamente entendida desde el concepto de índex como huella de la imagen fotográfica que, a su vez, se trae al frente con pintura. Por ello, la pintura surge de una forma mecanizada, y es ahí precisamente, en esa mecanicidad y neutralidad, donde se muestra la huella de la fotografía; es decir, se establece como un índex de la misma. Lo mecánico y lo técnico, características de lo fotográfico, sitúan a la pintura del alemán como un índex, en tanto que esa mecanicidad de la pintura muestra la huella de esas fotografías. Por tanto, las fotopinturas de Richter parten de una triple cuestión acerca de la relación que se establece entre el referente, el cuadro y 


\section{artnodes}

http://artnodes.uoc.edu

Agencia, imágenes e índex en las fotopinturas...

la realidad (Del Río 2008, 64). Estas cuestiones, fundamentalmente, se explican en:

Primera. El tipo de relación que guarda la imagen con su referente real:

Existe un deslizamiento de lo fotográfico hacia el soporte del lienzo. La imagen pintada es la huella de la fotografía. Guarda una relación de memoria a través de la mecanicidad y el antiestilo con la imagen referente. Esta relación memorística solo es posible desde la concepción fotográfica del cuadro, a través de las lógicas del índex.

Segunda. La trasposición de términos de la imagen foto a la imagen cuadro:

Las imágenes se trasladan punto por punto no añadiendo ni sustrayendo nada que no esté previamente en la foto. Es decir, la pintura se traslada desde la superficie de la fotografía a través de un procedimiento mecánico a la superficie del lienzo. En definitiva, Richter no añade nada a la pintura que no estuviese previamente inscrito en la fotografía. El antiestilo, los alisamientos, barridos y homogeneizaciones son las maneras de trabajar y de imprimirle el carácter mecánico a la imagen pictórica.

Tercera. El tipo de relación que guarda la imagen con la realidad:

Lo real es conectado a través de la indicialidad del propio medio pictórico, puesto que a través de esa huella el pintor crea un artefacto, al pasar de la objetividad de la foto a la objetualidad del cuadro. Lo real tiene cabida en la fisura existente entre el espacio del cuadro, hecho con pintura, y la imagen referencial, a través del desleimiento originado de forma mecánica con los barridos intencionados.

\section{Del signo indicial al artefacto visual a través del desleimiento de las imágenes}

Como hemos señalado, algo que distingue claramente este periodo en cuanto a formas de hacer son los difuminados intencionados. Los barridos en el cuadro ayudan a mantener esa ilusión de fotografía y huir de la idea de pintura convencional. Son mecánicos en tanto que se disponen mediante arrastres realizados con grandes brochas 0 cepillos, con el fin de igualar demarcaciones, contornos y homogeneizar la obra: son indispensables a la hora de justificar el antiestilo. La mecanicidad se comprende al esconder la mano del pintor y presentar la huella del aparato, en este caso, del cepillo que elimina cualquier recuerdo a la técnica pictórica, envolviendo a la obra en una inconcreción completa por su desleimiento. La semejanza únicamente conserva el recuerdo de lo que fue. Su nivel de concreción disminuye y la mímesis, en este sentido, se resiente; sin embargo, esto permite que la imagen conserve la ilusión de parecer una fotografía: alisada, homogénea, mecánica y, lo más importante, carente de estilo.
El hacer «algo borroso» provoca una separación intencionada entre lo pictórico y lo fotográfico. «Lo borroso es quizá también el intervalo entre la experiencia viva y su restitución codificada. Lo borroso es, quizá, la expresión del máximo realismo del que soy capaz» (Gerz 1975, 4). Lingwood escribe al respecto que este tipo de obras, las de Richter y las de Gerz, se oponen a lo espectacular, a cualquier efecto excitante 0 sorprendente (Lingwood 2004, 253).

Frente a la inmediatez de la fotografía y de su rápida visualización, la nueva condición de imagen pintada (es decir, de imagen que pertenece al territorio de lo pictórico a pesar de ser negada) refuerza la capacidad para ser observada con detenimiento. Se establece una pausa que, previamente en la fotografía, no se hacía. Todas las fotopinturas reiteran una pesada carga anodina, banal y antiartística, representada mediante la tecnicidad que Richter incorpora al cuadro creando verdaderos índices. Esta condición es compartida en todas las obras correspondientes a la clasificación como fotopinturas; sobre esto Richter escribe:

«No copio las fotografías con laboriosidad y gran esmero artesanal, sino desarrollo una técnica racional. Una técnica que es racional porque pinto como una cámara fotográfica y el resultado es tal como es porque utilizo otra manera de ver las cosas que surgió con la fotografía» (Richter 2003, 19).

La técnica racional está en negar el medio pictórico y concentrar los esfuerzos en crear la ilusión de una imagen técnica (indéxica) que recuerde a una fotografía y nunca a una pintura. Es un arte de re-producción. Las fotopinturas no pueden constituirse nunca como imágenes pictóricas al uso, entendidas como una imagen perteneciente al mundo de la historia de la pintura, debido a su condición fotográfica que las impide constituirse como tales. Pero esta hipótesis centra el debate en la posibilidad de que esa imagen se relacione con el mundo del arte, por su carácter de signo indicial, como huella 0 rastro, a partir de la mecanicidad que Richter le infunde. Asimismo, la obra establecida, a medio camino de la fotografía y la pintura, se convierte en una obra autónoma, desligada de su modelo referencial (Clemente 2004, 27). En palabras de Chevrier: «La imagen que reproduce la apariencia objetiva de una cosa sin ser una cosa en sí misma se ha convertido a su vez en una cosa, una cosa autónoma, separada de su modelo, desvinculada del objeto inicial» (Chevrier 2003, 209). Esta cosificación del signo indicial hace que la imagen pase de ser una imagen re-producida a un artefacto visual único y autónomo.

La imagen resultante solo puede entenderse a través de su vinculación con el índex en tanto que pintura. La imagen se presenta como un verdadero índex, como una pintura autónoma, rescatada de su banalidad e indiferencia visual en la que se encontraba cuando pertenecía al mundo fotográfico. Es decir, las fotografías pertenecen en un primer momento a la perfección técnica, sí, pero a su vez están condenadas a pertenecer a una más de su género; sufren, por tanto, 


\section{artnodes}

http://artnodes.uoc.edu

una indiferencia absoluta en su existencia. Por el contrario, trasladar la imagen a la superficie del lienzo le confiere un estatus absolutamente distinto de imagen autónoma que, como Richter señala, es rescatada de su indiferencia presentando una apariencia de cuadro pintado. Con este gesto, Richter le da validez a la propia fotografía. El rescate a la propia imagen de la indiferencia que posee a priori una imagen foto se consigue trasladando los términos de la foto al cuadro, 0 al crear la foto con pintura dándole la oportunidad de ser una obra pictórica, con todo lo que esto supone.

El propio Schilling destaca esto mismo en su comentario, a propósito de la imagen de Liz Kertelge de 1966: «Recuerda a las pálidas fotos que hay en las lápidas mediterráneas: un rostro anodino, ingenuo y bonito que despierta la curiosidad gracias a que un artista decidió que valía la pena reproducirlo» (Schilling 2003, 19). Richter es quien da validez a la fotografía convirtiéndola en cuadro. Asimismo, Leeber comenta que el cuadro pintado se eleva al rango de imagen, como reproducción, a la singularidad del icono, ya que una fotografía ya es un pequeño cuadro. Por ello, Richter explica que la fotografía «evita que estilices, que tengas una visión falsa, que des al tema una interpretación demasiado personal» (Leeber 1973, 15).

Otra vez, aquí vuelve a la idea del signo indéxico de fondo. Como señala Richter, la inmediatez propia de la fotografía impide que la juzgues, si es fotográfica indéxica, y aquí también indéxica por la tecnicidad de la misma, no puede ser nunca personal.Y esto, a Richter, es lo que verdaderamente le atrae. La fotografía permite pintar la realidad a la vez que no ideologiza a quien las traslada al cuadro, se muestra su literalidad, desde un repliegue de la imaginación (Foucault 2006, 75). Slavoj Žižek también advierte de la tensión entre el realismo fotográfico y su tránsito al lienzo en tanto que:

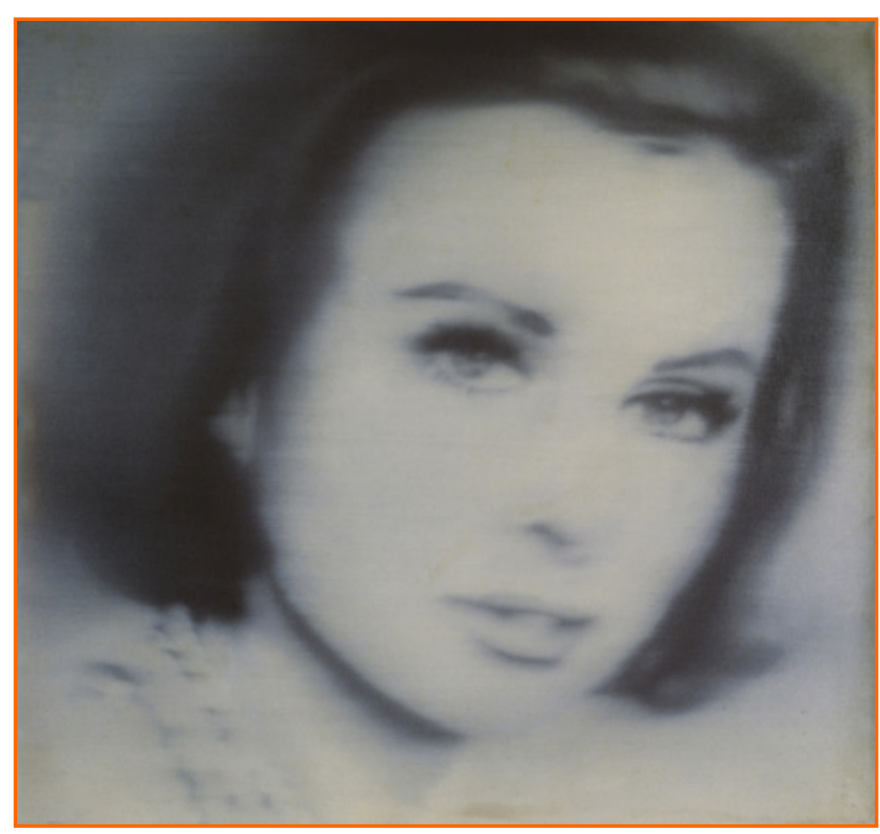

Imagen 2. Gerhard Richter. Retrato de Liz Kertelge. Óleo sobre lienzo, 1966.

Agencia, imágenes e índex en las fotopinturas...

«La lección definitiva de todo ello quizá se condense mejor en la tensión central de los cuadros de Gerhard Richter. Lo que representa una de sus series es el repentino tránsito del realismo fotográfico (ligeramente traspuesto/difuminado), [...] a la representación realista, como si, de súbito, nos hallásemos en la cara opuesta de una banda de Moebius» (Žižek 2004).

En ello, la obra de este periodo se caracteriza por reflejar la huella de la imagen a través de lo mecánico y lo técnico, frente a lo artesanal de cualquier pintura, además de jugar con lo real, a través de la representación fotográfica en términos indéxicos. Por ello, la imagen, en sus formas de aparecer, emerge con relación directa a la fotografía, precisamente por su condición de huella luminosa. El carácter indicial despliega sus resortes de homogeneización, alisamiento, reiteración del antiestilo y literalidad con el referente, tratamientos que traslada punto por punto el pintor a la obra. No hay una distinción de figura y fondo como en una pintura tradicional. No se priman unas partes frente a otras. Los empastes son inexistentes, se huye de la idea de pintura. Frente a eso, se nos trae al frente una imagen en blanco y negro en la que su cualidad formal se centra en el antiestilo. La superficie de la obra no debe romper la ilusión de observar una pseudo-fotografía creada con pintura: según Buchloh, el resultado debe ser liso y perfecto (Buchloh 1988, 33).

\section{Conclusiones}

La obra pictórica de Richter de este periodo se nos presenta como una obra alejada de la historia de la pintura, en una actitud de renuncia de la tradición y desde un pretendido amateurismo. Los términos de mecanicidad, tecnicidad y antiestilo relacionan estas obras directamente con el mundo de la fotografía. La anti composición del cuadro desde una lectura tradicional, así como las delgadas capas de aceite veladas que mantienen la ilusión de ver una fotografía, sumadas a los alisamientos en la superficie igualadora de las partes, señalan a estas pinturas como imágenes re-producidas en códigos fotográficos. Desde su propia convicción, solamente pueden establecerse transiciones a través de ese diluir, igualar y alisar la superficie mediante barridos. Una condición indispensable de la tecnicidad de la imagen, de la ilusión que pretende crear, y en su relación con un arte de máquina, es decir, con el signo indicial.

Asimismo, la ilusión fotográfica, la tecnificación meditada y ejecutada mecánicamente -pinto igual que una cámara de fotos- es la que le confiere este estatus de registro o huella en tanto que índex. La cuestión desde la que tratamos estas pinturas como índex se encuentra en el trasvase del signo, de la fotografía al cuadro, punto por punto. Su objetivo es el de realizar una imagen técnica, mecanizada y con la ilusión de ser inmediata (Flusser 2001, 40), como las fotografías, con un espacio abierto entre el cuadro y la 


\section{artnodes}

foto, tras el que poder representarlo todo sin un cuestionamiento 0 ideologización. En esa huida hacia adelante, donde la representación viene sancionada por una tecnología de la imagen, la foto se sitúa como un pretexto a través del cual no tener que pintar explícitamente el sentimiento y la intimidad de la escena.

Se trata, en definitiva, de rentabilizar el aprovechamiento mediante el juego de memorias, de recuerdos, de vínculos con el presente, pasado y futuro que, por su mismo carácter, aparece constantemente en cualquier uso del medio fotográfico (Hernández Sánchez 2005, 108). Es aquí donde el índex cobra de nuevo importancia, poniendo en relieve la indexalidad histórica (Osborne 2010 , 343) de la imagen que resulta de su inherente reproductibilidad (Durand 1999, 41). Las fotopinturas se nos presentan como unas imágenes técnicas grises, en una suerte de pretendidas fotografías, en el amplio sentido del término, pero que, a su vez, quedan relegadas a pinturas, por la condición de su propia técnica. Sin embargo, asumen un papel de rescatar a la imagen foto de su mísera existencia. Con estas pinturas, Richter da validez a la imagen fotográfica, en el paso de la imagen foto, a la imagen cuadro. El espacio de reflexión que se le otorga al cuadro es mucho mayor que el que se le otorga a una fotografía. Richter obtiene un artefacto visual al pasar de la objetividad de la imagen, a la objetualidad del cuadro, todo ello a través, como se dice, del índex. Trayecto también entre el análisis de la representación y el análisis de los signos (Foucault 2006, 83) que sitúa a las imágenes en el centro del discurso. El concepto de índex, desde su agencia, es el término que mejor explica las formas de hacer en Richter. Una apropiación del término, extraído del imaginario fotográfico que reescribe su presente, no en códigos pictóricos, sino en códigos fotográficos. La relación que se establece entre fotografía y pintura se desarrolla, por tanto, en términos de índex.

\section{Referencias bibliográficas}

Buchloh, B. H. D. 2003. «Conversaciones con Gerhard Richter». En Gerhard Richter Paintings. Chicago: Museum of Contemporary Art Chicago.

Chevrier, J. F. 2003. «El cuadro y los modelos de experiencia fotográfica». En Picazo, G. Ribalta, J. (ed.). Indiferencia y Singularidad. Barcelona: Gustavo Gili.

Clemente, J. L. 2004. «La pintura de Gerhard Richter, un reflejo de nosotros mismos». Arte y Parte, 49.
Danto, A. C. 2002. «Pintura, política y arte posthistórico». En Después del fin del arte. Barcelona: Paidós.

Del Río, V. 2008. «Las ruinas contemporáneas o el paisaje de la indiferencia». En Fotografía objeto. La superación de la estética del documento. Salamanca: Universidad de Salamanca.

Durand, R. 1999. El tiempo de la imagen. Ensayos sobre las condiciones de una historia de las formas fotográficas. Salamanca: Universidad de Salamanca.

Edwards, S. 2007. «Un paria en el mundo del arte: Richter marcha atrás». En ¿Qué ha sido de la fotografía? Barcelona: Gustavo Gili.

Foucault, M. 2006. Las palabras y las cosas: una arqueología de las ciencias humanas. Madrid: Siglo XXI.

Flusser, V. 2001. Una filosofía de la fotografía. Madrid: Síntesis.

Germer, S. 1989. Unbidden Memories, in Gerhard Richter: 18. Oktober 1977. London: Mitt Press Anthony D'Offay Gallery.

Gerz, J. 1975. «Les Pièces, París». Catálogo del Musée d'art moderne de la Ville de París y Musée d'art et d'industrie de Saint-Étienne. París: Museé d'Art Moderne de la Ville de Paris y Musée d'Art et d'Industrie de Saint-Étienne.

Hernández Sánchez, D. 2005. Pintura de apariencias. Gerhard Richter y las imágenes incompletas. Materiales de arte y estética. Salamanca: Luso Española.

Lang, L. 1995. «The Photographer's hand: Phenomenology in Politics». En J. P. Antoine, G. Koch y L. (ed.). Gerhard Richter. París: Dis Voir. Leeber, I. 1973. «Entrevista con Gerhard Richter». Chroniques de l'Art Vivant, 36.

Lingwood, J. 2004. «Otra Objetividad». En J. Ribalta (ed.). Efecto Real. Debates posmodernos sobre fotografía. Barcelona: Gustavo Gili.

Osborne, P. 1992. «Painting Negations: Gerhard Richter's Negatives». October, 62.

Osborne, P. 2010. Reproductibilidad y abstracción en el arte más allá de la estética. Ensayos filosóficos sobre arte contemporáneo. Murcia: CENDEAC.

Richter, G. 1995. The Daily Practice of Painting. Writings 1962-1993. Londres: Mitt Press Anthony D'offay Gallery.

Richter, G. 2003. «Notas 1964-1965». En G. Picazo, J. Ribalta (ed.). Indiferencia y Singularidad. Barcelona: Gustavo Gili.

Rose, B. 1979. American Painting: The Eighties. Buffalo: ThorenSidney.

Schilling, J. 2003. «El pintor Gerard Richter». En Gerhard Richter. Una colección privada. Catálogo de la exposición. Málaga: CAC Málaga.

Žižek, S. 2004. «Fotografía, documento, realidad: una ficción más real que la realidad misma». II Debates en torno a la fotografía. http//www.rebelion.org/noticia.php?id=15886. 


\section{artnodes}

http://artnodes.uoc.edu

Agencia, imágenes e índex en las fotopinturas...

\section{CV}

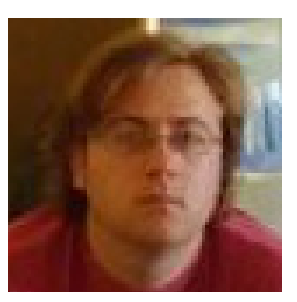

\section{Víctor Murillo Ligorred}

Universidad de Zaragoza

murillo.ligorred@gmail.com

vml@unizar.es

C/ Pedro Cerbuna, 12

50009 ZARAGOZA

Licenciado en Bellas Artes por la Universidad de Salamanca y doctor en Filosofía por la Universidad de Zaragoza con la tesis «Filosofías de la imagen: fotografía y pintura en la obra de Gerhard Richter» (sobresaliente cum laude).

Estancia de investigación nacional en el departamento de Educación de la Facultad de Educación, Universidad de Cantabria durante un mes.

Actualmente, profesor asociado del área de Didáctica de la Expresión Plástica, en el Departamento de Expresión Musical, Plástica y Corporal de la Facultad de Educación de la Universidad de Zaragoza.

Artista plástico con las líneas de investigación siguientes: estética, teoría del arte y praxis artística contemporánea. 